\title{
A mineralogia acessória do Amazonita Pegmatito Serra Branca: classificação de um pegmatito NYF na Província Borborema, Nordeste do Brasil
}

Accessory mineralogy of the Serra Branca Amazonite Pegmatite: classification of a NYF pegmatite in Borborema Province, Northeast Brazil

\author{
Igor Manoel Belo de Albuquerque e Souza' (D), Sandra de Brito Barreto ${ }^{1}$ (D), \\ Glenda Lira Santos ${ }^{1}$ (D), José Ferreira de Araújo Neto ${ }^{1}$ (D), Ignez de Pinho Guimarães ${ }^{1}$ \\ ${ }^{1}$ Universidade Federal de Pernambuco - UFPE, Departamento de Geologia, Avenida da Arquitetura, s/n, Cidade Universitária, \\ CEP 50740-550, Recife, PE, BR (igor.manoel.belo@gmail.com; sandradebritobarreto@gmail.com; glendaliraa@gmail.com; \\ araujoneto.geo@gmail.com; ignez@ufpe.br)
}

Recebido em 12 de setembro de 2019; aceito em 8 de julho de 2020

\begin{abstract}
Resumo
O campo pegmatítico de Vieirópolis é caracterizado pela ocorrência de pegmatitos com amazonita e/ou berilo. Esse campo contém pegmatitos do tipo NYF (Nb-Y-F) inseridos no Domínio Rio Grande do Norte (DRGN), fora do contexto da Província Pegmatítica do Seridó (PPS). O principal pegmatito desse campo, o Amazonita Pegmatito Serra Branca, destaca-se pela mineralização de megacristais de amazonita e por sua exploração como rocha ornamental de elevado valor econômico. Para caracterizar a paragênese e a química mineral das fases acessórias do Amazonita Pegmatito Serra Branca, além de elucidar a classificação e a natureza petrogenética desse pegmatito, foram utilizados dados de campo, petrográficos, difração de raios X e química mineral. O Amazonita Pegmatito Serra Branca ocorre como dique tabular com aproximadamente $3 \mathrm{~m}$ de espessura, de direção NW-SE e caimento $45^{\circ} \mathrm{WSW}$, caracterizado por apresentar uma zona composta por megacristais de amazonita e quartzo, e outra, por albita e quartzo sacaroidais. Apresenta vasta mineralogia acessória que compreende anglesita, biotita, bismutita, cerussita, columbita-(Mn), espessartina, helvina, fenaquita, fluorita, hematita, ilita, ilmenita, magnetita, montmorilonita, muscovita, piromorfita, pirocloro, rutilo e zircão. Destacando-se, também, atípicas mineralizações de sulfetos e a presença de beríliossilicatos reportados pioneiramente no contexto geológico da Província Borborema (PB). A paragênese mineral e a química dos minerais acessórios do Amazonita Pegmatito Serra Branca o classificam como pertence à família NYF da classe dos elementos raros, tipo da gadolinita, possivelmente associado a um magmatismo do tipo I.
\end{abstract}

Palavras-chave: Amazonita Pegmatito Serra Branca; Campo Pegmatítico de Vieirópolis; Paragênese mineral acessória; Pegmatitos NYF; Província Borborema.

\begin{abstract}
The Vieirópolis Pegmatite Field is characterized by amazonite- and/or beryl-bearing pegmatites. This field is composed of NYF-type pegmatites (Nb-Y-F) inserted in the Rio Grande do Norte Domain, outside the Seridó Pegmatite Province context. The main pegmatite body in this field, the Serra Branca Amazonite Pegmatite, stands out by the amazonite megacrysts mineralization and its exploitation as an ornamental rock with elevated economic value. In order to characterize the mineral chemistry and paragenesis of the accessory phases of the Serra Branca Amazonite Pegmatite, in addition to enlightening the classification and petrogenetic nature of this pegmatite, petrographic, X-ray diffraction, chemical and field data were used. The Serra Branca Amazonite Pegmatite occurs as a tabular dyke with approximately $3 \mathrm{~m}$ width, NW-SE strike and $45^{\circ} \mathrm{WSW}$ plunge, characterized by an amazonite and quartz megacrysts zone and a saccharoidal albite and quartz zone. This pegmatite presents a wide spectrum of accessory minerals composed by anglesite, bismutite, cerussite, columbite-( $\mathrm{Mn})$, spessartine, helvite, phenakite, fluorite, hematite, illite, ilmenite, magnetite, montmorillonite, muscovite, pyromorphite, pyrochlorine, rutile, and zircon. The presence of atypical sulfide mineralization and beryllium silicates are also highlighted as pioneering occurrences reported in the geological context
\end{abstract}


of the Borborema Province. The mineral paragenesis and chemistry of the accessory minerals from the Serra Branca Amazonite Pegmatite classifies this pegmatite as member of the NYF-family of the rare-element class, gadolinite type probably associated to an I-type magmatism.

Keywords: Serra Branca Amazonite Pegmatite; Vieirópolis Pegmatite Field; Accessory mineral paragenesis; NYF pegmatites; Borborema Province.

\section{INTRODUÇÃO}

O Nordeste brasileiro apresenta abundantes ocorrências de pegmatitos hospedados em rochas gnáissico-migmatíticas do embasamento, sequências supracrustais e/ou granitoides que compõem o mosaico geológico da Província Borborema (PB) (Almeida et al., 1981). Essa região contém uma das maiores províncias pegmatíticas graníticas em escala global, a Província Pegmatítica do Seridó (PPS) (Santos et al., 2014), composta de pegmatitos pertencentes à família LCT (Lítio-Césio-Tântalo), da classe de elementos raros, e aos subtipos berilo-columbita, berilo-columbita-fosfatos e espodumênio (Da Silva et al., 1995; Beurlen et al., 2008). A PPS tornou-se mundialmente famosa ao final da Segunda Guerra Mundial pela importante produção de minérios de tântalo e de espécimes gemológicas de turmalina, berilo, euclásio, quartzo e apatita (Beurlen et al., 2009; Soares et al., 2018). Ainda no contexto da PB, destacam-se os pegmatitos de filiação LCT do Distrito Pegmatítico Solonópole-Quixeramobim (Souza, 1985), conhecidos pela produção de gemas, minerais industriais e outros minerais de valor econômico (Vidal e Nogueira Neto, 2005).

Estudos recentes realizados por Barreto et al. (2016) definiram, fora do contexto geológico e geográfico da PPS, o Distrito Pegmatítico Vieirópolis (PB)-Tenente Ananias (RN)-Malta (PB). Nesse distrito, o Campo Pegmatítico de Vieirópolis destaca-se pela mineralização de grandes reservas de amazonita e/ou berilo. Classicamente, a presença de feldspatos amazoníticos está associada a pegmatitos pertencentes à família NYF (Nióbio-Ítrio-Flúor) (Martin et al., 2008). Dessa forma, as ocorrências de pegmatitos com filiação NYF do Campo Pegmatítico de Vieirópolis são as primeiras a serem registradas na PB. O Amazonita Pegmatito Serra Branca é o principal corpo dentro desse campo pegmatítico, ocorrendo como dique tabular mineralizado em megacristais de amazonita, e está localizado na Mina Amazon da empresa Granistone S.A. (Lira Santos et al., 2020). Esse pegmatito é atualmente explorado como rocha ornamental de excelente qualidade e de elevado valor comercial nos mercados nacional e internacional. Um grande espectro de silicatos, sulfetos, sulfatos, carbonatos e óxidos compõe a mineralogia acessória desse pegmatito.

A mineralogia acessória de pegmatitos NYF vem sendo investigada principalmente pela sua diversidade e importância econômica, bem como por auxiliar na classificação de pegmatitos graníticos (Brown, 1999). Observações criteriosas na assembleia mineral de pegmatitos, especialmente na mineralogia acessória, podem elucidar as diferentes categorias (classes, subclasses, tipos e subtipos) e famílias petrogenéticas (e.g., NYF, LCT ou NYF+LCT) dos pegmatitos graníticos (Černý e Ercit, 2005; Wise, 2013).

Este trabalho concentra-se no Amazonita Pegmatito Serra Branca e apresenta dados de campo, petrográficos, mineralógicos e químicos dos minerais acessórios que compõem esse pegmatito. Nesse sentido, almejamos:

- identificar as fases minerais acessórias por meio de técnicas analíticas;

- entender as relações petrográficas entre os minerais acessórios;

- caracterizar quimicamente os minerais;

- elucidar a tipologia do pegmatito por meio da sua paragênese mineral.

\section{GEOLOGIA REGIONAL}

A PB é constituída de um embasamento paleoproterozoico compreendendo complexos gnáissico-migmatíticos com pequenos núcleos arqueanos, parcialmente cobertos por rochas supracrustais com idade de deposição variando de Paleo- a Neoproterozoica (Van Schmus et al., 1995; Neves et al., 2008; Guimarães et al., 2016; Silva Filho et al., 2016). A estruturação atual da província é resultado da orogênese Brasiliana - Pan-Africana (650-580 Ma; Van Schmus et al., 2008), caracterizada por intenso magmatismo granítico que está associado, em grande parte, a um sistema de zonas de cisalhamento de alta temperatura transcorrentes destrais, com direção E-W, e ramificações sinistrais, com direção NE-SW (Vauchez e Egydio da Silva, 1992; Guimarães e Da Silva Filho, 1998; Ferreira et al., 1998; Neves e Mariano, 1999; Neves et al., 2000; Silva e Mariano, 2000). A PB foi dividida em três subprovíncias - Norte, Transversal e Sul (Van Schmus et al., 2011) (Figura 1A), sendo cada uma subdividida em domínios, exceto a transversal, dividida em terrenos, seguindo o modelo geotectônico de Santos (1995).

O Domínio Rio Grande do Norte (DRGN) compreende um embasamento de idade riaciana a orosiriana, limitado ao sul pelo Lineamento Patos e ao oeste pela Zona de Cisalhamento Senador Pompeu (Figura 1B), além de compreender a Faixa Seridó e os núcleos arqueanos do Domínio 
São José do Campestre. Assim como outras regiões da PB, essa subprovíncia foi intensamente afetada por intrusões graníticas de idade brasiliana, geralmente associadas a extensas zonas de cisalhamento transcorrentes (Jardim de Sá, 1994; Van Schmus et al., 1995; Dantas, 1997; Brito Neves et al., 2000). A DRGN subdivide-se entre os Domínios São José do Campestre, Rio Piranhas e Jaguaribeano, além da Faixa Seridó (Jardim de Sá, 1994; Brito Neves et al., 2000). O Domínio Rio Piranhas é composto por rochas paleoproterozoicas do embasamento pertencentes ao Complexo Caicó, definido como uma sequência litológica de alto grau metamórfico que abrange uma unidade metavulcanosedimentar mais antiga e uma unidade mais jovem que compreende rochas metaplutônicas, representadas por ortognaisses, migmatitos e milonitos (Meunier, 1964; Ferreira e Albuquerque, 1969; Medeiros, 2008). De acordo com Hackspacher et al. (1990), o metamorfismo nesta região varia da fácies xisto verde a anfibolito alto, podendo ter alcançado a fáceis granulito.

\section{GEOLOGIA LOCAL}

O Campo Pegmatítico de Vieirópolis compreende diques pegmatíticos mineralizados em amazonita intrudidos no plúton granítico Serra Branca, o qual intrude ortognaisses migmatizados do Complexo Caicó e granitos do plúton ediacarano Serra Negra, localizados entre as zonas de cisalhamento destrais Lastro e Vieirópolis (Araújo Neto et al., 2018) (Figura 2). O granito Serra Negra exibe granulação média a grossa e textura porfirítica marcante, apresentando composições sieníticas a monzoníticas, com biotita e anfibólios cálcicos como principais minerais acessórios. Os granitos do plúton Serra Branca são inequigranulares de granulação fina a média, metaluminosos a subaluminosos com composição variando entre álcali-feldspato sienítica a quartzo álcali-feldspato sienítica. Segundo Souza et al. (2020), os pegmatitos do campo de Vieirópolis foram originados por extremo fracionamento do magma dos granitos Serra Branca.

\section{MATERIAL E MÉTODOS ANALÍTICOS}

\section{Amostragem e preparações das seções}

Os minerais acessórios do pegmatito foram identificados utilizando 41 amostras analisadas por difração de raios X (DRX). Essas amostras foram escolhidas por apresentarem hábitos e cores diferentes da mineralogia principal do pegmatito, ou por sua ocorrência como cristais submilimétricos a milimétricos em cavidades centimétricas. A amostragem

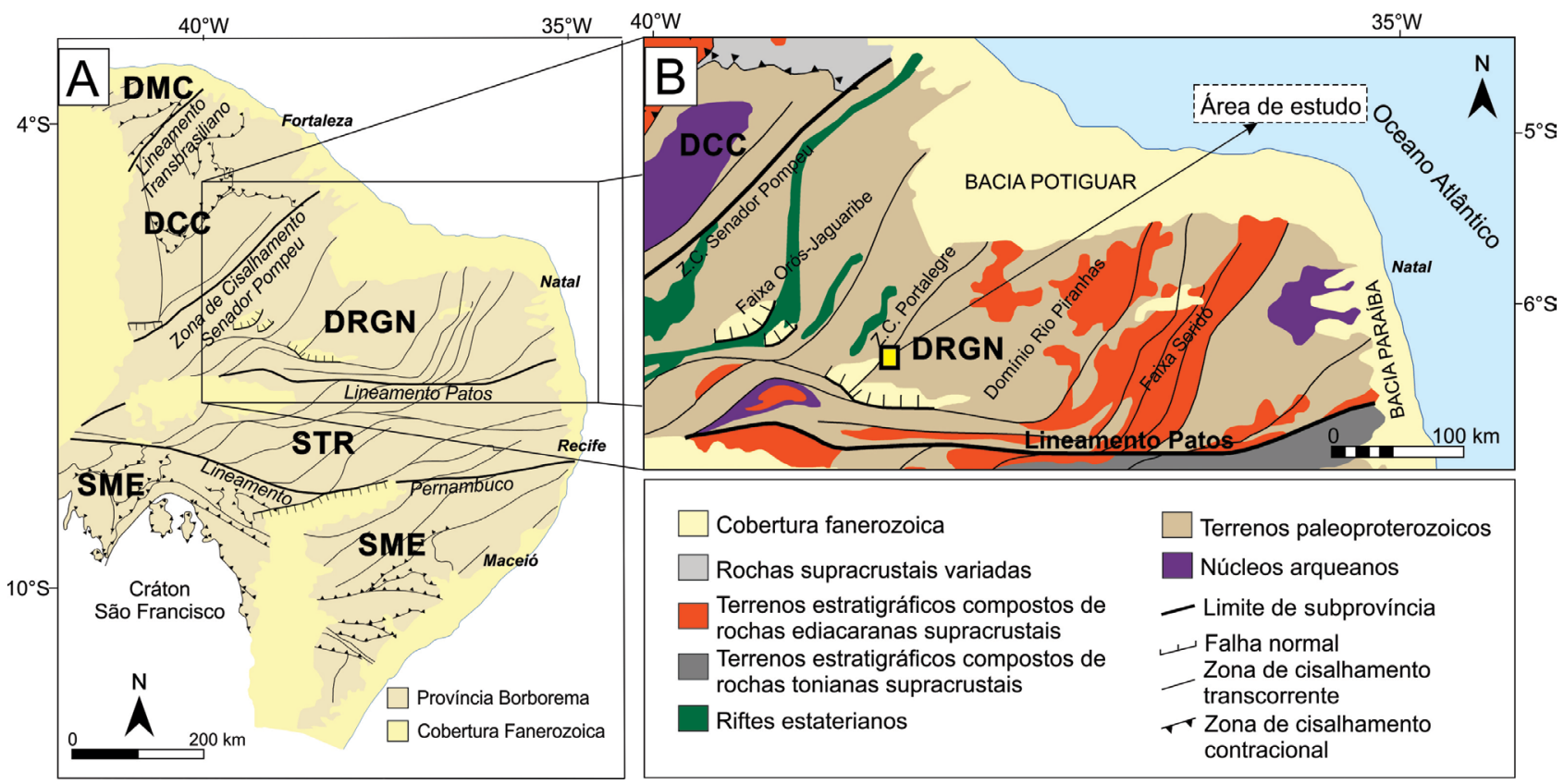

DMC: Domínio Médio Coreaú; DCC: Domínio Ceará Central; DRGN: Domínio Rio Grande do Norte; STR: Subprovíncia Transversal; SME: Subprovíncia Meridional. Fonte: modificado de Santos et al. (2014).

Figura 1. (A) Divisão tectônica da Província Borborema. (B) Destaque da área de estudo no Domínio Rio Grande do Norte. 

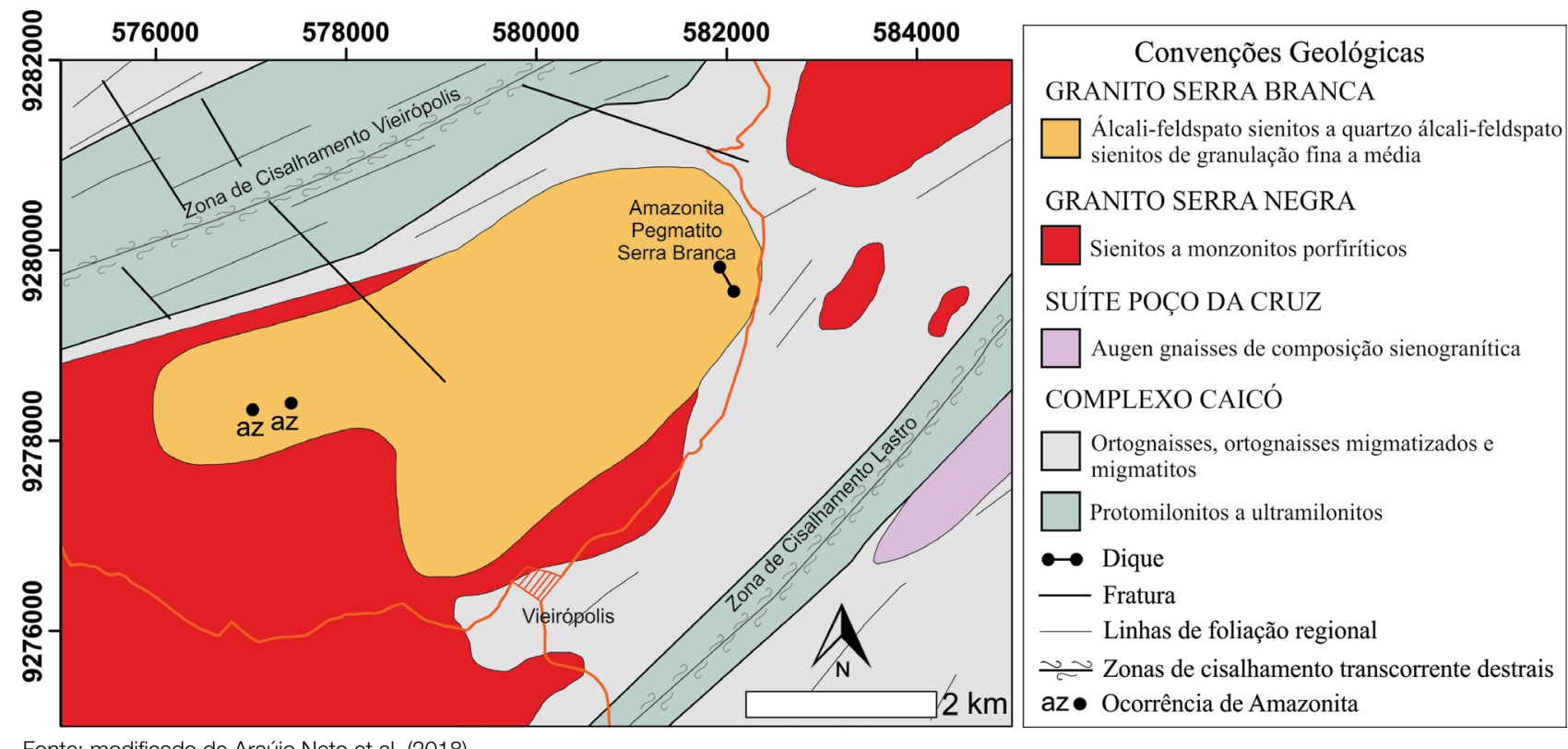

Fonte: modificado de Araújo Neto et al. (2018).

Figura 2. Mapa geológico local da região do Campo Pegmatítico de Vieirópolis.

foi realizada no pegmatito in situ, em blocos cortados para rocha ornamental e nos rejeitos da exploração da mina. Os minerais foram retirados utilizando-se espátulas de aço e recipientes de vidro, e posteriormente cominuídos até $150 \mu \mathrm{em}$ almofariz e pistilo de ágata. Essas preparações de amostras para DRX foram realizadas no Laboratório de Gemologia da Universidade Federal de Pernambuco (LabGem-UFPE).

Para os estudos petrográficos (luz transmitida e refletida) e a determinação da química mineral, foram selecionados cristais centimétricos de biotita e helvina e dos agregados de sulfetos visando a produção de seções delgadas polidas preparadas no LabGem-UFPE. Seções dos minerais foram coladas com cola epóxi em vidro e, em seguida, cortadas em serra de precisão Labcut 1010 e desbastadas em politriz Aropol VV (Arotec), utilizando discos de abrasão nos grãos $50,100,200,400,800,1.500$ e $3.000 \mu \mathrm{m}$. As seções selecionadas para análises pontuais de química mineral foram polidas sobre pano de veludo flocado (FVL) em politriz Aropol VV (Arotec) utilizando solução de diamante em suspensão, nas granulações 1 e $3 \mu \mathrm{m}$.

\section{Métodos analíticos}

\section{Microscopia por luz transmitida e refletida}

O estudo petrográfico foi realizado no LabGem-UFPE utilizando microscópio petrográfico Olympus BX-51, com capacidade de operar sob luz transmitida ou refletida, com aumento de 20 a 500x, acoplado a um sistema de captura digital de imagens - câmera DP26 e software OLYMPUS Stream.

\section{Difração de raios $X$}

As amostras pulverizadas dos minerais acessórios foram analisadas no Laboratório de Difração de Raios X do Departamento de Agronomia da Universidade Federal Rural de Pernambuco (UFRPE) e no Laboratório de Tecnologia Mineral da UFPE. Foi utilizado o difratômetro Bruker, com tubo de $\mathrm{Cu}$, potência de $1.200 \mathrm{VA}(40 \mathrm{kV}, 30 \mathrm{~mA})$ e velocidade de goniômetro de $1^{\circ}$ /minuto na faixa de $2 \theta$ de $3^{\circ}$ a $70^{\circ}$.

\section{Microssonda eletrônica}

Para a aquisição da química dos elementos maiores e menores dos minerais acessórios, foram realizadas análises em cinco seções delgadas polidas no Laboratório de Microssonda Eletrônica (LASON) do Instituto de Geociências da Universidade de Brasília (UnB). As seções delgadas foram recobertas previamente por átomos de carbono por meio de um sistema de recobrimento a vácuo Edwards Auto 306. Para obtenção dos dados químicos, foi utilizada a microssonda JEOL modelo JXA-8230, equipada com microscópio eletrônico de varredura (scanning electron microscope - SEM), cinco espectrômetros de raios X por dispersão de comprimento de onda (wavelength dispersive $x$-ray spectrometer - WDS) e um espectrômetro de raios 
$\mathrm{X}$ por dispersão de energia (energy dispersive X-ray spectrometer - EDS). O sistema foi operado para análise de silicatos e sulfetos. Foram empregados cristais analisadores TAP, LDE1, PETJ, LIF e LIFH. Os padrões internos de calibração utilizados foram: albita $(\mathrm{Na})$, microclina $(\mathrm{K})$, wollastonita ( $\mathrm{Si} \mathrm{e} \mathrm{Ca),} \mathrm{topázio}(\mathrm{F})$, vanadinita $(\mathrm{V}, \mathrm{Cl}$ e $\mathrm{Pb})$, $\mathrm{TiMnO}_{3}(\mathrm{Ti}$ e $\mathrm{Mn})$, andradita $(\mathrm{Fe})$, forsterita $(\mathrm{Mg})$, barita (Ba), pollucita (Cs), $\mathrm{ZnS}(\mathrm{Zn})$, apatita $(\mathrm{P}) \mathrm{CuFeS}_{2}(\mathrm{Cu}), \mathrm{Cr}_{2} \mathrm{O}_{3}$ $(\mathrm{Cr}), \mathrm{NiO}(\mathrm{Ni}), \mathrm{RbSi}(\mathrm{Rb})$ e addeleyita (Zr). Empregaram-se os seguintes parâmetros analíticos: voltagem de aceleração de $15 \mathrm{kV}$, corrente de $10 \mathrm{nA}$, diâmetro do feixe eletrônico de $1 \mu \mathrm{m}$ e tempo de contagem no pico de $10 \mathrm{~s}$. Imagens de microscopia óptica por meio de câmera $\mathrm{CCD}$ acoplada à microssonda e imagens de composição (COMPO) geradas por elétrons retroespalhados foram utilizadas para selecionar os pontos de análise desejados.
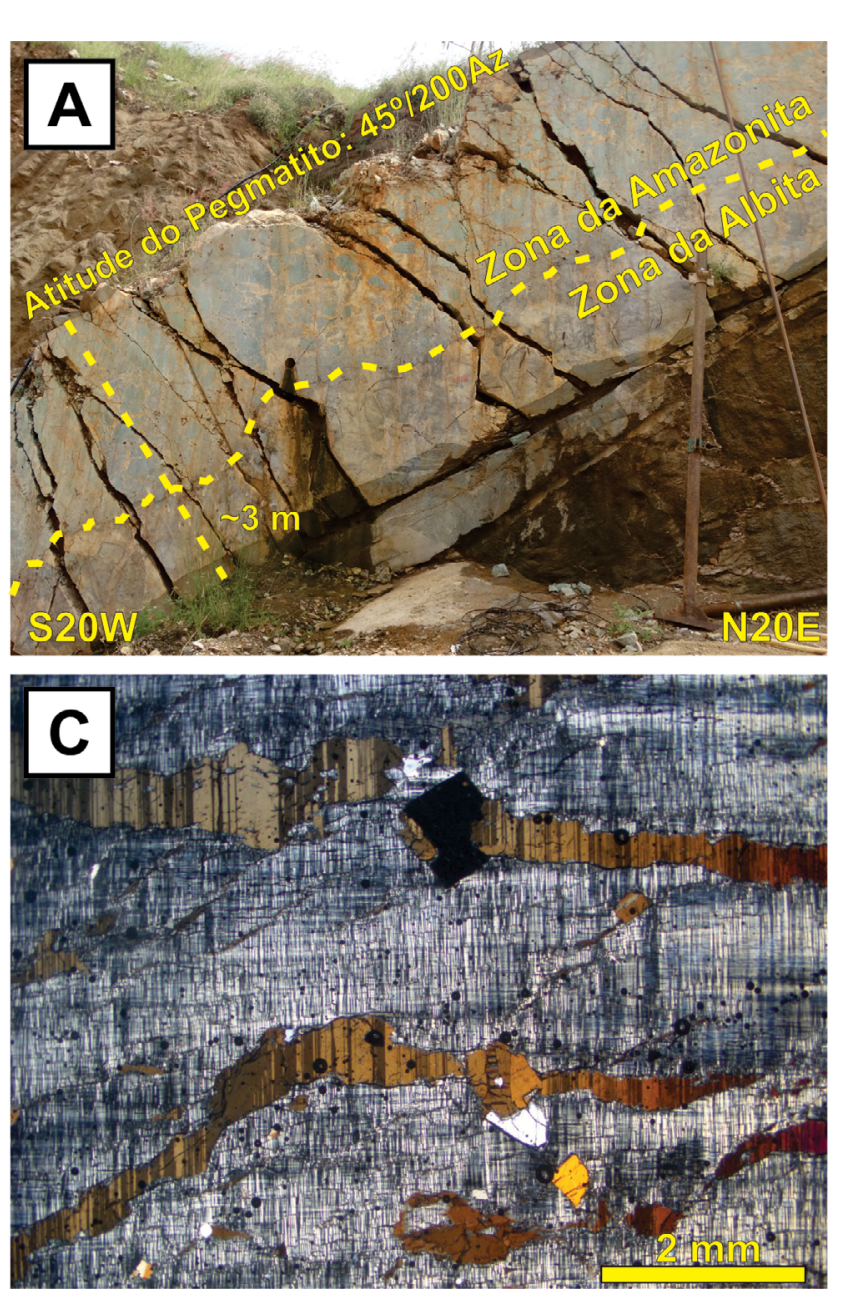

\section{RESULTADOS}

\section{Aspectos de campo e petrografia}

\section{Amazonita Pegmatito Serra Branca}

O Amazonita Pegmatito Serra Branca apresenta-se na forma de dique tabular de aproximadamente $3 \mathrm{~m}$ de espessura e $800 \mathrm{~m}$ de comprimento de área aflorante, com direção NW-SE e caimento $45^{\circ} \mathrm{WSW}$. As texturas e distribuições dos seus minerais se dão de forma complexa: a abundância dos minerais formadores desse pegmatito varia do contato inferior ao superior do pegmatito com a rocha encaixante. Duas zonas podem ser identificadas por predominância da ocorrência de dois tipos de feldspatos: a zona da amazonita e a zona da albita (Figura 3A). A zona da amazonita totaliza,
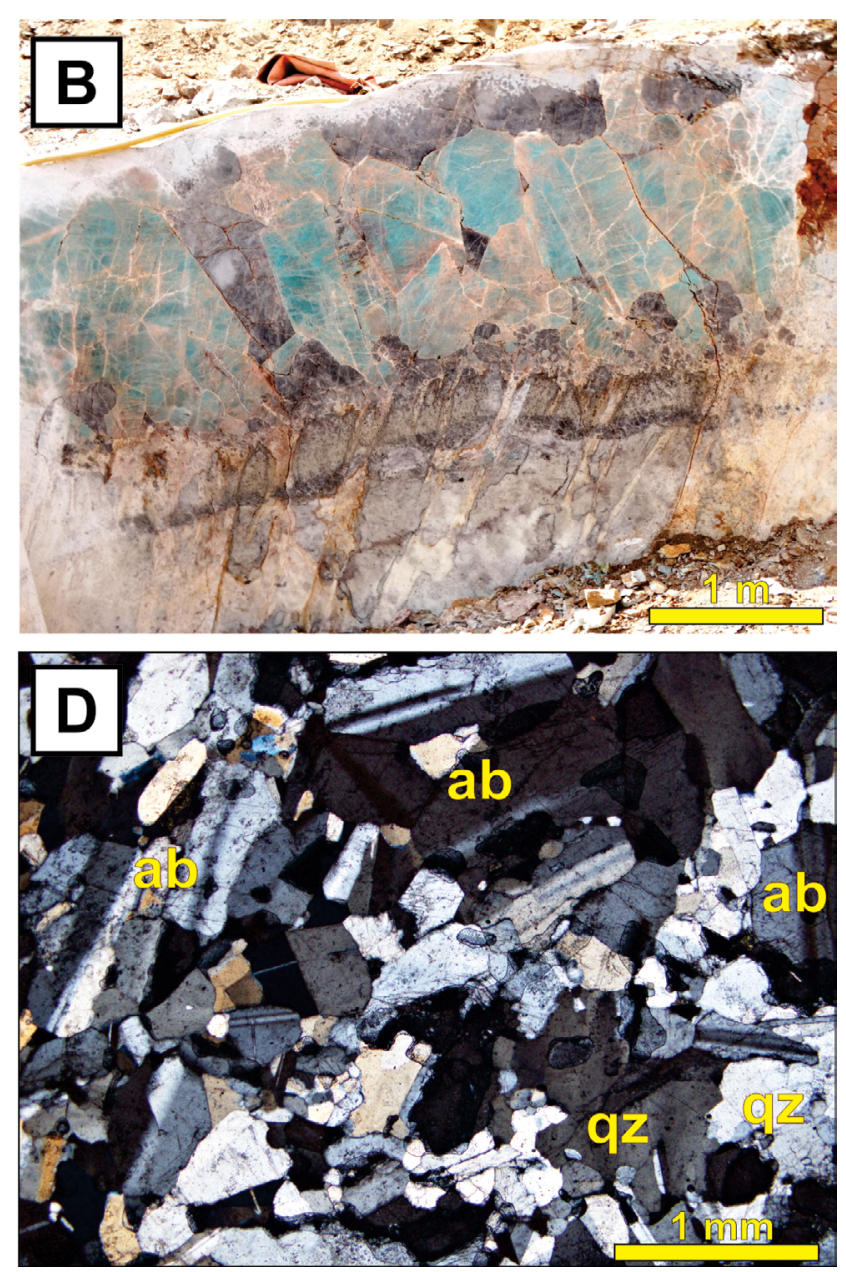

ab: albita; qz: quartzo.

Figura 3. (A) Dique tabular aflorante do Amazonita Pegmatito Serra Branca com direção NW-SE e caimento $45^{\circ}$ WSW. (B) Megacristais de amazonita e quartzo na porção superior do pegmatito, e predominância de albita e quartzo sacaroidais na porção inferior. (C) Amazonita com geminação cruzada e veios pertíticos de albita com geminação polissintética da Lei da Albita, além de cristais milimétricos de albita com coloração amarelada, observada por microscopia de luz transmitida a nicóis cruzados. (D) Microtextura inequigranular da zona da albita. 
em média, cerca de $75 \%$ do volume do pegmatito e se localiza na parte superior do dique, enquanto a zona de albita é encontrada principalmente na parte inferior do dique, mas, por vezes, ocorre inserida na zona da amazonita.

A zona da amazonita é caracterizada pela mineralização de megacristais de amazonita e quartzo. A amazonita ocorre como cristais verde azulados prismáticos centimétricos a métricos, idiomórficos, por vezes com intercrescimento gráfico com o quartzo (Figura 3B). Microscopicamente, a amazonita apresenta-se com geminação cruzada e veios pertíticos que têm geminação polissintética da Lei da Albita (Figura 3C). O quartzo ocorre como cristais de dimensão centimétrica, subidiomórficos a idiomórficos, por vezes exibindo hábito pseudo-hexagonal, que apresentam-se com coloração esfumaçada a incolor (Figura 3B). Ambos os cristais estão intensamente fraturados, e entre seus contatos e nas fraturas dos megacristais da amazonita ocorre o preenchimento por albita sacaroidal e/ou placosa, porém em pouco volume. A zona da amazonita exibe ampla variedade de minerais acessórios, sendo a biotita o mais abundante, ocorrendo como lamelas centimétricas de coloração preta (Figura 3C). São observadas mineralizações irregulares de sulfetos centimétricos hospedados entre os megacristais de amazonita e quartzo (Figura 4A), compostas essencialmente por sulfetos primários e em menor proporção por fases minerais de alteração. Além desses, a assembleia de minerais acessórios da zona da amazonita também apresenta: helvina, ilmenita, fluorita, muscovita, fenaquita, piromorfita, rutilo, pirocloro, montmorilonita e ilita. Entre os megacristais são observados dois tipos de cavidades que ocorrem nos cristais de amazonita $\mathrm{e}$ nas porções sacaroidais da zona da amazonita, ambas apresentando minerais secundários distintos.

A zona da albita é composta essencialmente de albita esbranquiçada sacaroidal e quartzo hialino sacaroidal (Figura 3B) e, em menor frequência, albita de hábito tabular (clevelandita). Apesar da granulometria fina, micropetrograficamente a rocha apresenta textura inequigranular e observam-se hábitos lamelares da clevelandita (Figura 3D). Nessa zona ocorrem raros cristas centimétricos de amazonita e quartzo esfumaçado pseudo-hexagonal, ambos intensamente fraturados e preenchidos por material sacaroidal. Além da biotita em hábito lamelar, a zona de albita tem como minerais acessórios: ilmenita, zircão, columbita-(Mn), espessartina e minerais do supergrupo do pirocloro.

O contato entre as zonas da amazonita e albita é marcado por mudança abrupta de granulometria, além de apresentar ocorrências de fitas de quartzo e lamelas centimétricas a milimétricas de biotita. A interação entre as zonas é caracterizada por texturas penetrativas da zona de albita intrudindo os megacristais da zona da amazonita (Figura 3B), além da substituição parcial a total de prismas de amazonita por material sacaroidal.

\section{Petrografia da mineralogia acessória}

A biotita é a fase acessória com maior representatividade volumétrica, ocorre como lamelas de coloração preta, intercaladas ou inclusas nos megacristais da zona da amazonita, sem apresentar orientação preferencial, podendo chegar a $10 \mathrm{~cm}$ de comprimento (Figura 4B). Na zona da albita, apresenta-se como pequenas lamelas dispersas na massa sacaroidal.

A helvina, um raro beríliossilicato de manganês, ocorre inclusa na amazonita ou no interior de cavidades centimétricas preenchidas por albita e quartzo sacaroidais nesses cristais, apresentando-se na forma de triângulos e prismas euédricos a subédricos de até $3 \mathrm{~cm}$ de comprimento, com coloração marrom-escura a marrom-avermelhada (Figura 4C). Microscopicamente, os cristais de helvina apresentam grande quantidade de fraturas (Figura 4D), sendo parte dessas preenchida por material mineral de granulação muito fina que não pode ser identificado por meio das técnicas aplicadas neste trabalho. A fenaquita é outro beríliossilicato que ocorre em cristais translúcidos, subédricos na zona da amazonita dentro de cavidades centimétricas, em que predomina quartzo e albita sacaroidal.

A ilmenita ocorre como cristais anédricos com coloração preta e brilho metálico, atingindo máximo de $3 \mathrm{~mm}$ de comprimento, principalmente inclusos nos megacristais de amazonita. Sua presença é evidenciada por auréolas de alteração avermelhadas no feldspato (Figura 4E). Ocorrendo em pouca abundância, a columbita-(Mn) apresenta-se como cristais anédricos de coloração preta, comumente associada a pequenas lamelas de biotita. Hematita e magnetita aparecem juntas na zona da amazonita, ambos minerais como cristais anédricos de coloração preta com bordas alaranjadas a amareladas e magnetismo fraco, e ocorrem preferencialmente inclusos nos cristais de quartzo esfumaçados e nas porções sacaroidais da zona da amazonita.

Nas cavidades centimétricas dos cristais de amazonita observam-se cristais euédricos de fluorita amarela a esverdeada com até $4 \mathrm{~cm}$ de comprimento, muscovita euédrica com até $5 \mathrm{~mm}$, rutilo e pirocloro com hábitos pulverulentos e coloração avermelhada e roxa, respectivamente, além da ocorrência de cristais milimétricos de helvina, biotita, ilmenita e piromorfita. Montmorilonita e ilita ocorrem como produtos de alteração do feldspato amazonítico nessas cavidades.

A zona da amazonita hospeda poucas mineralizações centimétricas a decimétricas de sulfetos. Essa mineralização sulfetada está distribuída aleatoriamente entre os megacristais, apresentando contatos irregulares com os feldspatos amazoníticos e quartzo (Figura 4A). Os sulfetos apresentam duas colorações predominantes de brilho metálico, preta e prata, que correspondem à galena e à aikinita, respectivamente. Em seções delgadas polidas observadas por microscopia de luz refletida percebe-se que o feldspato e o quartzo têm contatos retilíneos com os sulfetos e podem ocorrer como inclusões arredondadas (Figura 4F). A galena é o mineral 

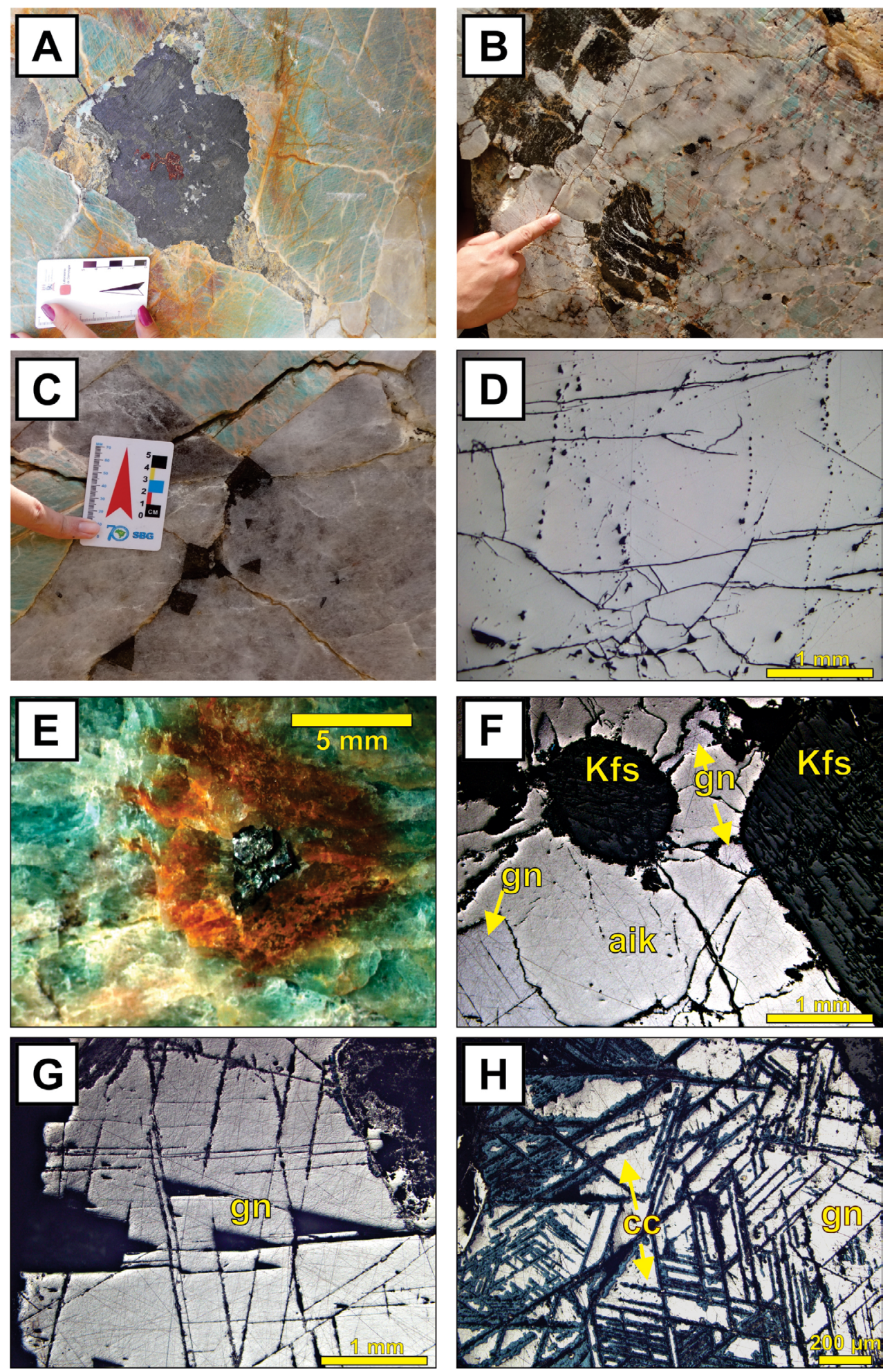

Figura 4. (A) Agregados de sulfetos com coloração preta e prata, composto essencialmente de galena e aikinita entre os megacristais da zona da amazonita. (B) Cristais de biotita na zona de amazonita. (C) Cristais retangulares e triangulares de helvina encrustados nos megacristais da zona da amazonita. (D) Cristal de helvina fraturado observado por microscopia de luz refletida. (E) Foto em lupa binocular de um cristal de ilmenita encrustado em amazonita. (F) Ocorrência de galena (gn) e aikinita (aik) em contato com cristais euédricos de feldspato potássico amazonítico (Kfs). (G) Galena (gn) exibindo destaques triangulares. $(\mathrm{H})$ Intercrescimento de calcocita $(\mathrm{cc})$ nos planos de clivagens de galena (gn). 
mais abundante da mineralização sulfetada, apresentando coloração cinza, três planos de clivagem perfeitos e destaques triangulares (Figura 4G). A aikinita ocorre com coloração amarela pálida e refletividade maior do que a galena (Figura 4F), comumente apresentando fraturas preenchidas por silicatos e minerais secundários nesse mineral. A calcocita, somente observável por meio do estudo micropetrográfico, ocorre com cor azul e intercrescida ao longo dos três planos de clivagem da galena, em que são observadas microtexturas penetrativas partindo do plano de clivagem em direção ao centro dos cristais de galena (Figura 4H).

Além da mineralização em sulfetos, cavidades alongadas com até $0,5 \mathrm{~cm}$ de comprimento podem apresentar mistura de fosfatos, sulfatos e carbonatos secundários pulverulentos.

\section{Caracterização mineralógica por difração de raio $X$}

Para a caracterização da mineralogia acessória do Amazonita Pegmatito Serra Branca, foram realizadas 41 análises de difração de raios X (DRX). Os dados dessas análises foram indexados e interpretados no software X'PERT High Score Plus e o resumo das fases minerais que compõem o pegmatito está na Tabela 1.

Foram identificadas 12 fases minerais acessórias associadas diretamente aos megacristais da zona da amazonita

Tabela 1. Resumo dos minerais acessórios por zonas do Amazonita Pegmatito Serra Branca.

\begin{tabular}{lll}
\hline $\begin{array}{l}\text { Minerais } \\
\text { Acessórios }\end{array}$ & $\begin{array}{c}\text { Zona da } \\
\text { Amazonita }\end{array}$ & $\begin{array}{c}\text { Zona da } \\
\text { Albita }\end{array}$ \\
\hline Aikinita & \\
Anglesita & - \\
Biotita & \\
Bismutita & \\
Cerussita & \\
Columbita-(Mn) & - \\
Espessartina & \\
Fenaquita & \\
Fluorita & \\
Galena & \\
Helvina & \\
Hematita & \\
llita & \\
Ilmenita & \\
Magnetita & \\
Montmorillonita & \\
Muscovita & \\
Piromorfita & \\
Pirocloro & \\
Rutilo & \\
Zircão & \\
\hline
\end{tabular}

e/ou aos minerais com hábito sacaroidal da zona albita. Os difratogramas revelaram a presença de beríliossilicatos raros, como fenaquita e helvina (Figuras 5A e 5B). Além dos silicatos de Be, foram identificadas biotita (Figura 5C), fluorita (Figura 5D), muscovita, magnetita, ilmenita, rutilo, hematita, columbita-(Mn), pirocloro, piromorfita e ilita.

A identificação dos minerais constituintes das mineralizações sulfetadas por DRX permitiu a confirmação de suas principais fases minerais, galena e aikinita (Figura 6A), previamente observadas por microscopia de luz refletida (Figuras 4E, 4F, 4G). Os difratogramas revelaram que cavidades alongadas dessas mineralizações são preenchidas pelos minerais anglesita (Figura 6B), bismutita (Figura 6C) e cerussita (Figura 6D), que ocorrem como produtos secundários resultado da alteração de galena e aikinita.

\section{Química mineral}

\section{Biotita}

Foram analisados, por microssonda eletrônica, seis cristais de biotita do Amazonita Pegmatito Serra Branca. A composição química desses cristais é apresentada na Tabela 2. Os cristais de biotita apresentam conteúdos intermediários a baixos de ferro, com valores de $\mathrm{Fe} \#[\mathrm{Fe} /(\mathrm{Fe}+\mathrm{Mg})]$ variando entre 0,29 e 0,41 . No diagrama $\mathrm{Al}^{\mathrm{IV}}$ versus $\mathrm{Fe}$ estão dispostos próximo ao campo das flogopitas (Figura 7). A biotita apresenta concentrações elevadas de $\mathrm{TiO}_{2}$ (entre 1,15 e 1,91\% peso), $\mathrm{MnO}$ (entre 0,59 e $2,39 \%$ peso) e em $\mathrm{Rb}_{2} \mathrm{O}$ (entre 1,40 e $1,98 \%$ peso).

\section{Helvina}

As análises por microssonda eletrônica dos minerais do grupo da helvina foram realizadas em duas amostras de monocristais em vários pontos ao longo de cada cristal, totalizando $12 \mathrm{e}$ 18 pontos analisados para as amostras AM104 e CAVA01, respectivamente. $\mathrm{O}$ conteúdo de $\mathrm{BeO}$ foi calculado por meio da fórmula estequiométrica com base em 22 átomos de oxigênio e 6 átomos de berílio por unidade de fórmula. A média das análises das amostras AM104 e CAVA01 estão na Tabela 3. As variedades das espécies minerais do grupo da helvina podem ser determinadas com base na ocupação do sítio-M [considerando a fórmula geral $\mathrm{M}_{8} \mathrm{Be}_{6}\left(\mathrm{SiO}_{4}\right)_{6} \mathrm{~S}_{2}$ ] pelos cátions $\mathrm{Zn}, \mathrm{Fe}$ e Mn (Zito e Hanson, 2017). Projetando as análises dos cristais estudados de beríliossilicatos no diagrama triangular genthelvina-danalita-helvina (Figura 8), esses cristais são classificados como helvina stricto sensu, em que há predominância de Mn, pequenas variações nas proporções de Zn e Fe.

\section{Mineralizações de sulfetos}

Para a caracterização da mineralização sulfetada do Amazonita Pegmatito Serra Branca, foram realizadas 23 análises em 

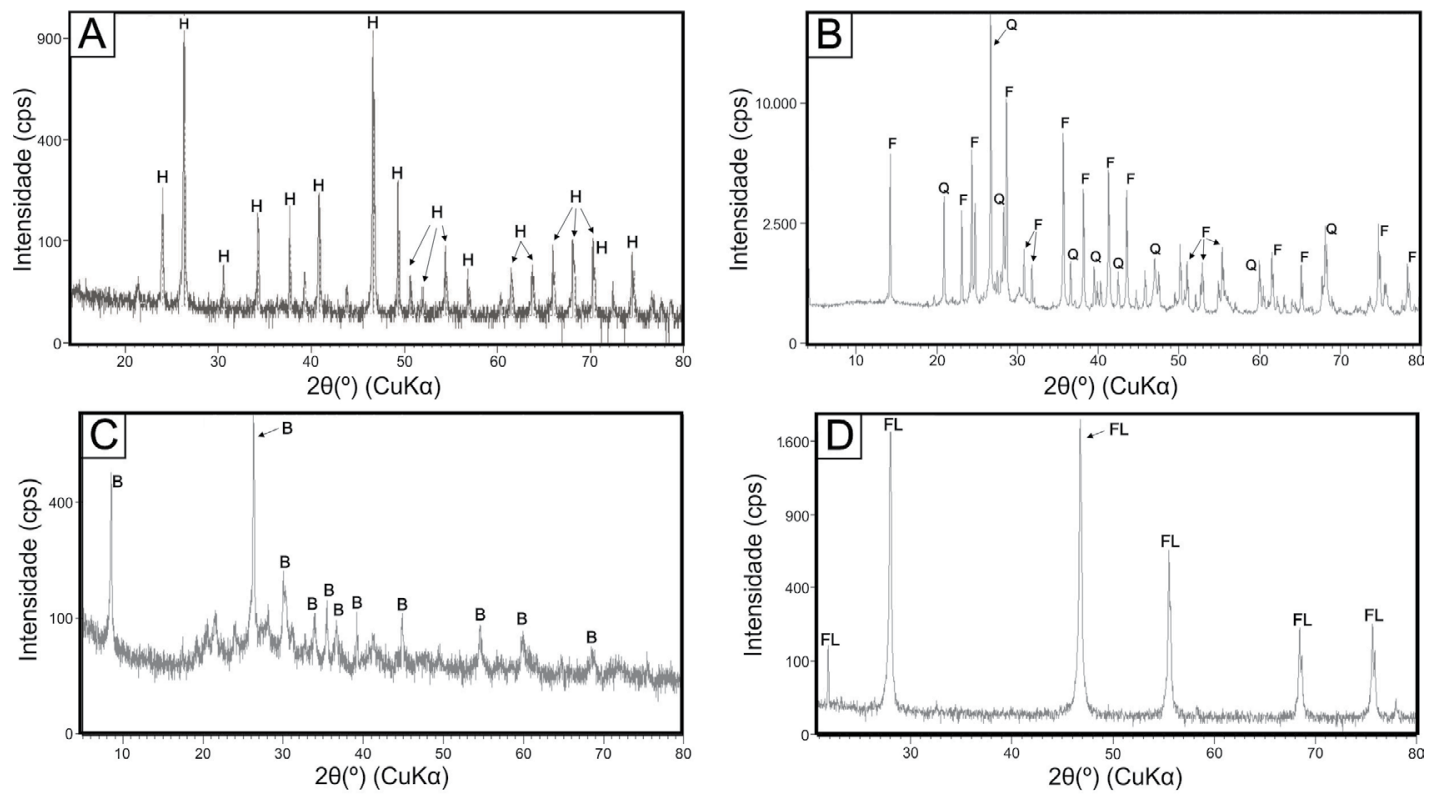

$$
\begin{array}{lll}
H=\text { Helvina } & Q=\text { Quartzo } & F L=\text { Fluorita } \\
F=\text { Fenaquita } & B=\text { Biotita } &
\end{array}
$$

Figura 5. Difratogramas evidenciando presença das seguintes fases minerais no Amazonita Pegmatito Serra Branca: (A) helvina, (B) fenaquita e quartzo, (C) biotita, (D) fluorita.
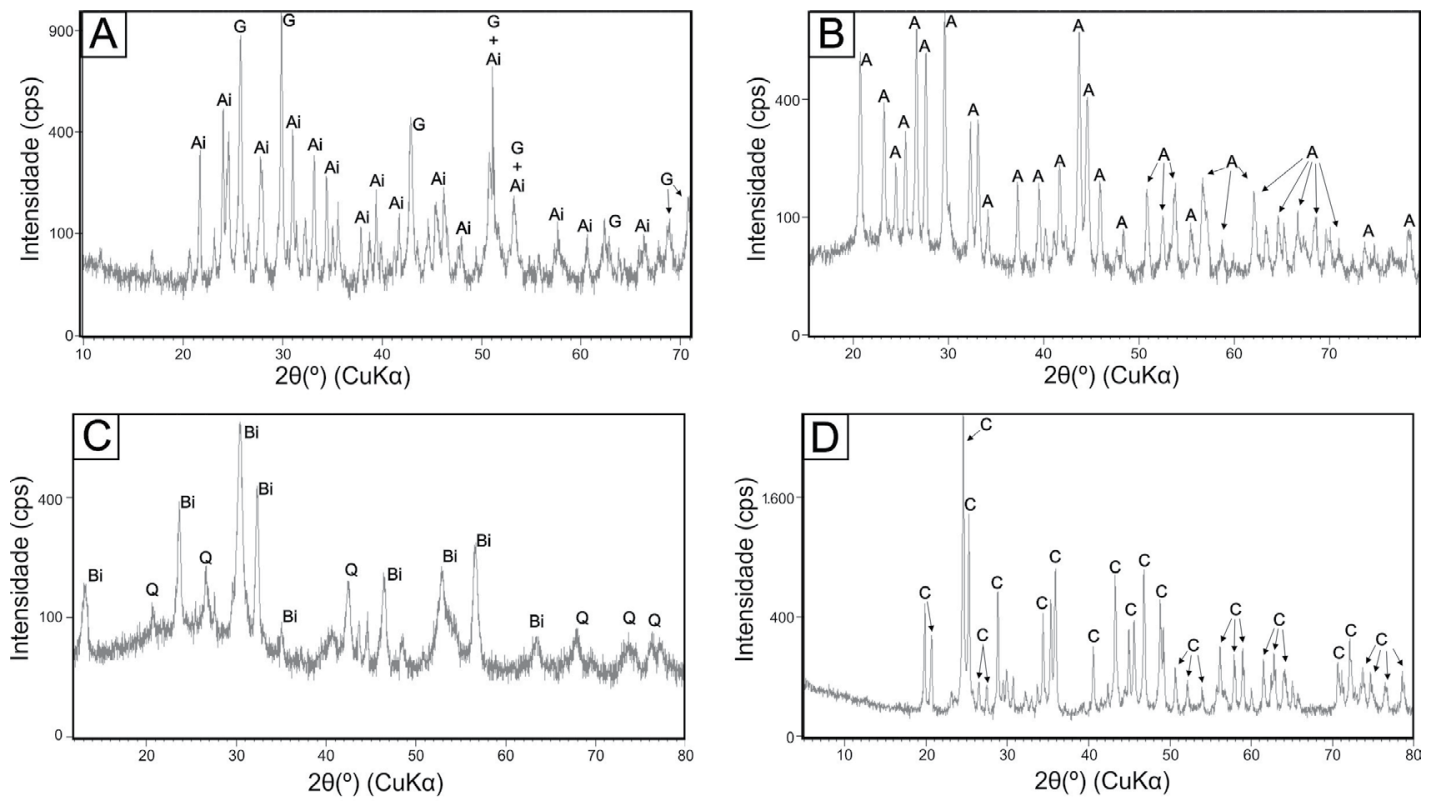

$$
\begin{array}{lll}
\mathrm{Ai}=\text { Aikinita } & \mathrm{A}=\text { Anglesita } & \mathrm{Q}=\text { Quartzo } \\
\mathrm{G}=\text { Galena } & \mathrm{Bi}=\text { Bismutita } & \mathrm{C}=\text { Cerussita }
\end{array}
$$

Figura 6. (A) Difratograma de aikinita e galena das mineralizações sulfetadas. Difratogramas dos minerais secundários das mineralizações sulfetadas: (B) anglesita, (C) bismutita e quartzo, (D) cerussita. 
Tabela 2. Composição química dos cristais de biotita.

\begin{tabular}{|c|c|c|c|c|c|c|}
\hline Amostras & $\begin{array}{c}\text { Amz- } \\
35\end{array}$ & $\begin{array}{l}\text { Amz- } \\
104.1\end{array}$ & $\begin{array}{l}\text { Amz- } \\
104.2\end{array}$ & $\begin{array}{l}\text { Amz- } \\
104.3\end{array}$ & $\begin{array}{l}\text { Amz- } \\
104.4\end{array}$ & $\begin{array}{l}\text { Amz- } \\
104.5\end{array}$ \\
\hline \multicolumn{7}{|c|}{ Elementos maiores em \% peso } \\
\hline $\mathrm{SiO}_{2}$ & 39,40 & 39,06 & 40,26 & 38,25 & 39,53 & 43,44 \\
\hline & 1,50 & 1,15 & 1,57 & 1,78 & 1,49 & 1,91 \\
\hline $\mathrm{Al}_{2} \mathrm{O}_{3}$ & 10,90 & 9,25 & 9,97 & 8,95 & 9,58 & 9,70 \\
\hline $\mathrm{FeO}$ & 15,70 & 14,57 & 13,46 & 14,84 & 13,96 & 10,48 \\
\hline Mnc & 30 & & 1,74 & 2,39 & 2,13 & 0,59 \\
\hline Ms & 2,40 & 11,98 & 13,15 & 12,28 & 12,71 & 14,48 \\
\hline $\mathrm{Ca}$ & 00 & 0,14 & 0,06 & 0,05 & 0,04 & 0,03 \\
\hline $\mathrm{Na}$ & 00 & 09 & ,09 & 0,04 & 0,05 & 0,00 \\
\hline $\mathrm{K}_{2} \mathrm{C}$ & 8,90 & 8,40 & 9,03 & 8,92 & 8,81 & 8,98 \\
\hline $\mathrm{Rb}_{2}$ & 1,40 & 1,42 & 1,40 & 1,53 & 1,98 & 1,71 \\
\hline $\mathrm{F}$ & 3,90 & 4,76 & 5,25 & 4,76 & 5,16 & 6,31 \\
\hline $\mathrm{Cl}$ & 0,00 & 0,05 & 0,00 & 0,01 & 0,00 & 0,03 \\
\hline $\mathrm{BaC}$ & 0,00 & 0,00 & 0,07 & 0,03 & ,03 & 0,09 \\
\hline Total & 96,40 & 92,80 & 96,06 & 93,82 & 95,47 & 97,73 \\
\hline \multicolumn{7}{|c|}{$\begin{array}{l}\text { Átomos por unidade de fórmula } \\
\text { (com base em } 22 \text { átomos de oxigênio) }\end{array}$} \\
\hline $\mathrm{Si}$ & 5,50 & 6,40 & 6,36 & 6,27 & 6,33 & 6,62 \\
\hline $\mathrm{Ti}$ & 20 & 14 & 0,19 & 0,22 & 0,18 & 0,22 \\
\hline All & 80 & 1,60 & 1,64 & 1,73 & 1,67 & 1,38 \\
\hline $\mathrm{Al}^{\mathrm{M}}$ & 00 & & 0,21 & 0,00 &, 14 & 0,37 \\
\hline $\mathrm{Fe}$ & & & & 2,04 & ,87 & ,34 \\
\hline & & & & 0,33 & 0,29 & ,08 \\
\hline & & & & 3,00 & ,04 & 29 \\
\hline & & & & 0,01 &, 01 & ,01 \\
\hline & & & & 0,01 & ,02 & ,00 \\
\hline K & & & 2 & 1,87 & 1,80 & 75, \\
\hline $\mathrm{Rb}$ & & & 0,14 & 0,16 & 0,20 & 0,17 \\
\hline $\mathrm{OH}$ & 30 & 52 & 1,3 & 1,53 & 1,39 & , ,95 \\
\hline $\mathrm{F}$ & & 2,47 & 2,62 & 2,47 & 2,61 & 3,04 \\
\hline $\mathrm{Cl}$ & & 01 & 0,00 & 0,00 & 0,00 & 0,01 \\
\hline Fe\# & 0,40 & 0,41 & 0,36 & 0,40 & 0,38 & 0,29 \\
\hline
\end{tabular}

sulfetos, sendo 12 análises de galena, 4 de aikinita e 7 de calcocita. A média dessas análises é apresentada na Tabela 4. A galena é composta essencialmente por $\mathrm{S}$ (12,97 a 13,31\% peso) e $\mathrm{Pb}(84,68$ a $87,22 \%$ peso), apresenta concentrações significativas de Mo ( 0,78 a $0,94 \%$ peso $)$ e Bi $(0,1$ a $0,22 \%$ peso). Segundo Foord e Shawe (1989), bismuto é um elemento traço comum em galena, porém a ocorrência de molibdênio é incomum. Além de Bi e Mo, os cristais de galena analisados apresentam baixas concentrações de $\mathrm{Zn}$ $(0,009$ a $0,07 \%$ peso $), \operatorname{Se}(0,01$ a $0,08 \%$ peso $), \mathrm{Cd}(0,03$ a $0,15 \%$ peso), $\mathrm{Fe}(0,007$ a $0,03 \%$ peso), Co $(0,006$ a $0,06 \%$ peso), $\mathrm{Cu}(0,001$ a $0,089 \%$ peso $)$ e Ni $(0,002$ a $0,018 \%$ peso $)$.

Aikinita é um mineral composto majoritariamente por $\mathrm{S}$ (16,56 a $16,84 \%$ peso), $\mathrm{Bi}$ (39,3 a 40,39\% peso), $\mathrm{Pb}(33,72$ a $34,53 \%$ peso) e $\mathrm{Cu}(10,69$ a $11,14 \%$ peso). Os elementos traços são Zn (0,006 a $0,084 \%$ peso), Se $(0,01$ a $0,032 \%$

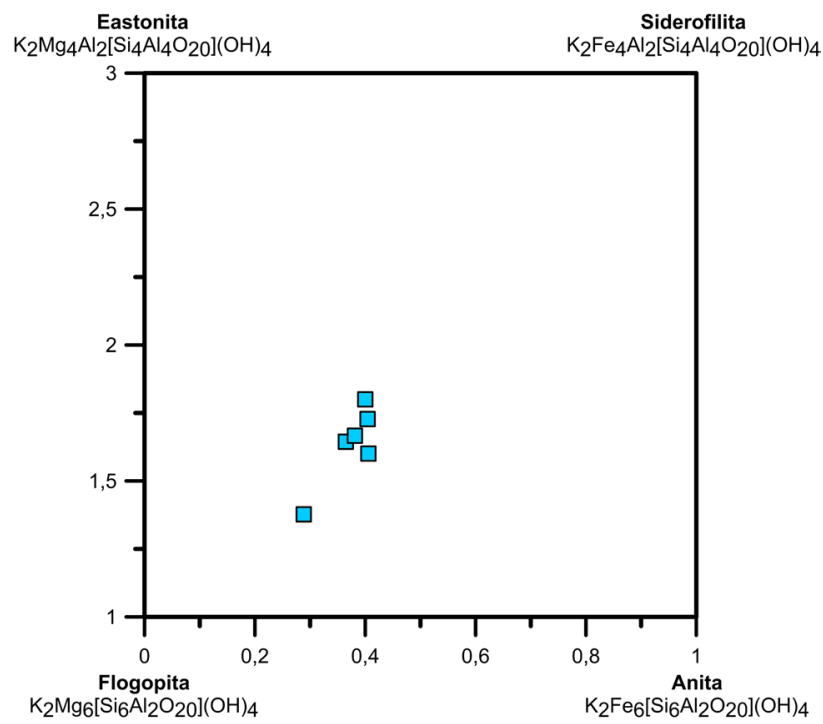

Figura 7. Diagrama químico Fe\# vs Alv para a classificação dos cristais de biotita, segundo Speer (1984).

Tabela 3. Composição química dos cristais de helvina.

\begin{tabular}{lcccccc}
\hline Amostra & AM104 & CAVA01 & \multicolumn{3}{c}{ AM104 CAVA01 } \\
\hline \multicolumn{4}{c}{ Átomos por unidade de } \\
Elementos maiores em \% peso fórmula (com base em \\
22 átomos de oxigênio \\
e 6 átomos de Be)
\end{tabular}

Média de 12 e 18 pontos analisados das amostras AM104 e CAVA01, respectivamente. $\mathrm{BeO}$ calculado com base em 22 átomos de oxigênio e 6 de berílio por unidade de fórmula; *ferro total, representado por FeO. 
peso), $\mathrm{Cd}(0,01$ a $0,08 \%$ peso $), \mathrm{Fe}(0,012$ a $0,036 \%$ peso $)$, Co $(0,002$ a $0,043 \%$ peso $)$ e Mo $(0,475$ a $0,5 \%$ peso).

A calcocita é composta por $\mathrm{S}$ ( 26,57 a $29,8 \%$ peso), $\mathrm{Cu}$ (59,2 a $63,1 \%$ peso ) e $\mathrm{Pb}(1,37$ a $6,5 \%$ peso), apresentando altos teores de $\mathrm{Ag}$ (3,3 a $4,53 \%$ peso) e $\mathrm{Bi}(0,75$ a $1,57 \%$ peso), e baixas concentrações de $\mathrm{Zn}(0,03$ a $0,2 \%$ peso), Se $(0,01$ a $0,1 \%$ peso $), \mathrm{Cd}(0,01$ a $0,06 \%$ peso $)$ e Mo $(0,04$ a $0,14 \%$ peso).

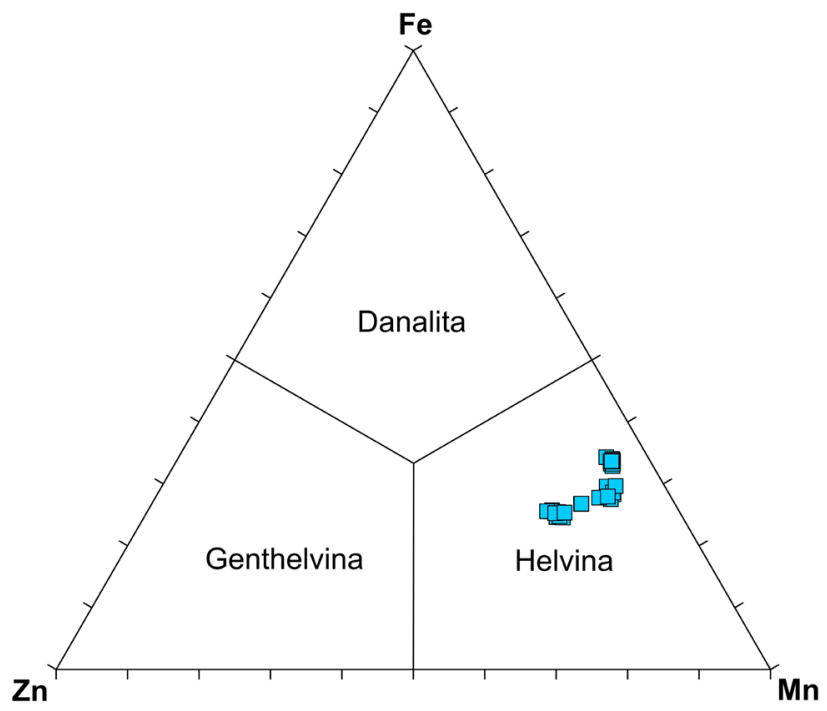

Figura 8. Diagrama triangular genthelvina-danalita-helvina de classificação dos minerais do grupo da helvina, segundo Glass et al. (1944).

Tabela 4. Composição química dos sulfetos do Pegmatito Serra Branca.

\begin{tabular}{lccc}
\hline Elementos & Galena & Aikinita & Calcocita \\
\hline Percentagem em & peso $(\%$ peso) & & \\
$\mathrm{As}$ & 0,00 & 0,00 & 0,00 \\
$\mathrm{Zn}$ & 0,01 & 0,05 & 0,10 \\
$\mathrm{Ga}$ & 0,00 & 0,00 & 0,00 \\
$\mathrm{Se}$ & 0,04 & 0,02 & 0,07 \\
$\mathrm{~S}$ & 13,11 & 16,74 & 28,81 \\
$\mathrm{~Pb}$ & 85,52 & 34,17 & 3,29 \\
$\mathrm{Bi}$ & 0,15 & 39,95 & 0,96 \\
$\mathrm{Cd}$ & 0,08 & 0,03 & 0,02 \\
$\mathrm{Fe}$ & 0,01 & 0,02 & 0,01 \\
$\mathrm{Co}$ & 0,02 & 0,02 & 0,01 \\
$\mathrm{Cu}$ & 0,02 & 10,90 & 60,37 \\
$\mathrm{Ni}$ & 0,00 & 0,01 & 0,01 \\
$\mathrm{Mo}$ & 0,85 & 0,50 & 0,07 \\
$\mathrm{Au}$ & 0,00 & 0,00 & 0,00 \\
$\mathrm{Ag}$ & 0,00 & 0,00 & 4,22 \\
$\mathrm{Total}$ & 99,82 & 102,40 & 97,94 \\
\hline
\end{tabular}

\section{DISCUSSÃO}

\section{Classificação do Amazonita Pegmatito Serra Branca}

OAmazonita Pegmatito Serra Branca apresenta mineralizações expressivas de megacristais de feldspatos amazoníticos que o caracterizam como pegmatito da família NYF (Martin et al., 2008). Além disso, a mineralogia acessória é importante para a elucidação da tipologia dos pegmatitos graníticos, de modo que a associação de minerais acessórios e principais (amazonita) permite afirmar que o pegmatito estudado apresenta características mineralógicas que indicam a sua filiação NYF, como previamente indicado por Souza et al. (2020) e Lira Santos et al. (2020). A ocorrência de minerais acessórios que contêm elementos de alto potencial iônico (high field strength elements - HFSE), como pirocloro, rutilo e ilmenita (Černý e Ercit, 2005), a escassa presença de fases minerais ricas em alumínio e lítio (características de pegmatitos da família LCT) e a predominância de biotita como principal mineral acessório do grupo das micas (Wise, 2017) corroboram a filiação NYF do Amazonita Pegmatito Serra Branca. Ainda, a paragênese mineral enriquecida em HFSE classifica esse pegmatito como da subclasse de elementos raros-ETR (subclasse rare-element - REE) (Černý e Ercit, 2005) e a presença virtual de Be, representada pela helvina e fenaquita, permite classificá-lo como pertencente ao tipo gadolinita (Wise, 1999).

Wise (2013) propôs um diagrama ternário $\mathrm{Al}_{2} \mathrm{O}_{3}-\mathrm{MgO}-\mathrm{FeO}_{\text {total }}$ em que se projetam os dados de química mineral de biotita para discriminar os pegmatitos das famílias NYF e LCT, além de separar os pegmatitos dos tipos NYF-I e NYF-A. Projetando os dados químicos da biotita do Amazonita Pegmatito Serra Branca, observa-se que os cristais de biotita pertencem ao campo dos pegmatitos NYF-I (Figura 9). Concordantemente, Souza et al.

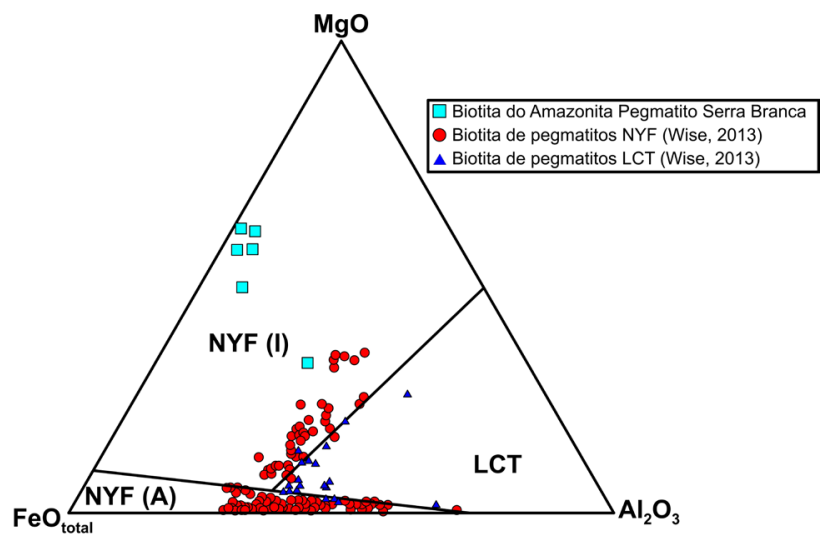

NYF (I): pegmatitos do tipo NYF oriundo de magmatismo do tipo I; NYF (A) pegmatitos do tipo NYF oriundo de magmatismo do tipo A.

Figura 9. Dados químicos dos cristais de biotita plotados no diagrama ternário $\mathrm{FeO}_{\text {total }}, \mathrm{MgO}$ e $\mathrm{Al}_{2} \mathrm{O}_{3}$ para classificação de pegmatitos do tipo NYF e LCT, segundo Wise (2013). 
(2020) sugerem que o Amazonita Pegmatito Serra Branca se originou de melts enriquecidos em elementos incompatíveis, produto do extremo fracionamento do magmatismo granítico do Granito Serra Branca, o qual consiste em um granito do tipo I. Sendo assim, pode-se sugerir que o Amazonita Pegmatito Serra Branca se classifica como pertencente à família NYF associado ao magmatismo de um granitoide do tipo I.

\section{Mineralização sulfetada do Amazonita Pegmatito Serra Branca}

Os pegmatitos podem conter uma complexa assembleia de sulfetos (Černý e Harris, 1978; Černý et al., 2001), embora ocorram principalmente como inclusões de outros minerais por serem susceptíveis à oxidação (London, 2008). Os sulfetos também podem ocorrer ao longo de fraturas na zona de núcleo de quartzo ou às margens da zona de núcleo, associados às fases minerais tardias no interior dos pegmatitos (Seaman, 1974). No contexto dos pegmatitos graníticos, o Amazonita Pegmatito Serra Branca apresenta rara ocorrência de sulfetos e sulfossais, representada por galena e aikinita. Salienta-se que a aikinita é um mineral raramente reportado em pegmatitos e mais comumente associado a veios hidrotermais (e.g., Cryolite pegmatite; Seaman, 1974). Além desses minerais, o pegmatito estudado apresenta a calcocita intercrescida ao longo dos planos de clivagem da galena (Figura 4G), possivelmente como produto de estabilização da galena em relação ao seu conteúdo de $\mathrm{Cu}$. Nas cavidades dessas mineralizações sulfetas ocorrem os minerais secundários anglesita e cerussita, resultados comuns do intemperismo da galena (Bowles et al., 2011).

Landes (1933) propõe que a ocorrência de minerais metálicos em pegmatitos se dá pela precipitação de soluções hidrotermais que se formam pela cristalização dos estágios tardios dos magmas/fluídos pegmatíticos. Os sulfetos são formados em pegmatitos em condições de baixa temperatura, geralmente abaixo de $450^{\circ} \mathrm{C}$ (London, 2018). Os minerais galena e aikinita do Amazonita Pegmatito Serra Branca são caracterizados petrograficamente por constituírem fases minerais posteriores à consolidação dos megacristais da zona da amazonita (Figura 4E). Baseando-se nas evidências de campo e petrográficas, essas fases minerais sulfetadas provavelmente foram originadas de fluídos pegmatíticos residuais da cristalização dos minerais da zona da amazonita. Além disso, esse mesmo fluido, possivelmente, formou os cristais milimétricos de albita, clevelandita e quartzo da zona da albita que penetram a zona da amazonita.

\section{Beríliossilicatos do Amazonita Pegmatito Serra Branca}

Apesar da baixa concentração de berílio na crosta terrestre, os beríliossilicatos são comuns em pegmatitos (London,
2008) e apresentam mineralogia diversificada em pegmatitos graníticos (Černý, 2002). Para os pegmatitos do tipo NYF, os principais minerais de Be são os pertencentes ao grupo da gadolinita (London, 2008), e para os pegmatitos NYF, quimicamente mais evoluídos, são os berilos (Wise, 2017). De acordo com Černý (2002), as espécies minerais fenaquita e helvina são raras em pegmatitos graníticos, ocorrendo associadas às fases paragenéticas tardias em pegmatitos do tipo NYF. Martin-Izard et al. (1995) reportam a ocorrência de fenaquita metassomática nos pegmatitos do depósito gemológico de Franqueira (Galícia, Espanha), enquanto Ragu (1994) relaciona a ocorrência de helvina às atividades hidrotermais em rochas graníticas.

No Amazonita Pegmatito Serra Branca, a fenaquita ocorre exclusivamente em cavidades da zona da amazonita, com predominância de quartzo e albita sacaroidal, enquanto a helvina ocorre encrustada nos megacristais da zona da amazonita ou em cavidades junto à fenaquita. Os cristais de helvina provavelmente apresentam duas gerações distintas:

- uma representada por cristais tetraédricos inclusos nos cristais de amazonita;

- uma associada aos cristais de fenaquita nas cavidades, possivelmente por causa da atuação de fluidos tardios relacionadas ao alojamento tardio da zona da albita.

Porém, são necessários estudos mais detalhados, com foco nessa paragênese mineral, para elucidar essa sequência de cristalização.

As ocorrências de fenaquita e helvina no Brasil restringem-se aos estados do Amazonas, da Bahia, do Espírito Santo, de Goiás e de Minas Gerais (MINDAT, 2020). As identificações dessas espécies minerais como constituintes minerais do Amazonita Pegmatito Serra Branca são as primeiras ocorrências a serem reportadas no contexto geológico da PB.

\section{CONCLUSÃO}

O Amazonita Pegmatito Serra Branca caracteriza-se como um raro corpo pegmatítico que contém importantes reservas de amazonita e mineralizações sulfetadas atípicas, além de apresentar ampla assembleia mineral acessória composta por anglesita, biotita, bismutita, cerussita, columbita-(Mn), espessartina, helvina, fenaquita, fluorita, hematita, ilita, ilmenita, magnetita, montmorilonita, muscovita, piromorfita, pirocloro, rutilo e zircão.

As mineralizações sulfetadas e os beríliossilicatos de cavidades que ocorrem no pegmatito estudado podem estar relacionados à cristalização de fases mais tardias, as quais estão associadas à alocação de albita e quartzo sacaroidais da zona albita. Os raros beríliossilicatos do Amazonita Pegmatito Serra Branca, helvina e fenaquita, 
são as primeiras ocorrências desses minerais reportadas na PB.

A paragênese e a química dos minerais acessórios permitiram a confirmação da filiação petrogenética NYF do Amazonita Pegmatito Serra Branca e a classificação na subclasse dos pegmatitos de elementos raros-ETR do tipo da gadolinita. Por meio da química dos cristais de biotita e da definição do pegmatito como produto do magmatismo granítico do Granito Serra Branca, foi possível indicar que o Amazonita Pegmatito Serra Branca é do tipo NYF derivado de magmatismo do tipo I. A tipologia NYF desse pegmatito revela para a $\mathrm{PB}$ uma natureza diferente e relevante de pegmatitos, comparada aos conhecidos pegmatitos LCT presentes na PPS, Nordeste do Brasil.

\section{AGRADECIMENTOS}

Os autores são agradecidos à empresa GRANISTONE, o suporte à nossa pesquisa e as amostras do pegmatito cedidas. À Coordenação de Aperfeiçoamento de Pessoal de Nível Superior (CAPES), as bolsas de mestrado concedidas a Igor Manoel Belo de Albuquerque e Souza e Glenda Lira Santos. Nós gostaríamos de expressar nossa gratidão ao Professor Dr. Axel Müller, por sua assistência durante esta pesquisa. Ao Professor Dr. Nilson Botelho (Universidade de Brasília), as análises de microssonda eletrônica. Ao Professor Dr. Pedro Luiz Guzzo (Universidade Federal de Pernambuco) e à Professora Dra. Sheila Maria Bretas Bittar Schulze (Universidade Federal Rural de Pernambuco), as análises de difração de raios X.

\section{REFERÊNCIAS}

Almeida, F. F. M., Hasui, Y., Brito Neves, B. B., Fuck, R. (1981). Brazilian structural provinces: an introduction. Earth Science Reviews, 17(1-2), 1-29. https://doi. org/10.1016/0012-8252(81)90003-9

Araújo Neto, J. F., Lira Santos, G., Souza, I. M. B. A., Barreto, S. B., Santos, L. C. M. L., Bezerra, J. P. S., Carrino, T. A. (2018). Integration of remote sensing, airborne geophysics and structural analysis to geological mapping: a case study of the Vieirópolis region, Borborema Province, NE Brazil. Geologia USP. Série Cientifica, 18(3), 89-103. https://doi. org/10.11606/issn.2316-9095.v18-140834

Barreto, S. B., Muller, A., Araujo Neto, J. F., Bezerra, J. P. S., Souza, I. M. B. A., França, R. H. M., Santos, L. C. M. L. (2016). Vieirópolis Pegmatite Field, Northwest of Paraíba State, Brazil: New Occurrences of Amazonite Pegmatites. In: M. I. Jacobson (Ed.). Second Eugene E.
Foord Pegmatite Symposium: Abstracts, Short Papers, Posters and Program. Denver: Friends of Mineralogy. p. 24-26. Disponível em: $<\mathrm{http}: / /$ friendsofmineralogycolorado. org/wp-content/uploads/2016/07/Abstract_book-Foord_ pegmatite_symposium_with_covers.pdf $>$. Acesso em: 15 jul. 2020.

Beurlen, H., Da Silva, M. R. R., Thomas, R., Soares, D. R., Olivier, P. (2008). Nb-Ta-(Ti-Sn)-oxide mineral chemistry as tracers of rare-element granitic pegmatite fractionation in the Borborema Province, Northeast Brazil. Mineralium Deposita, 43, 207-228. http://dx.doi. org/10.1007/s00126-007-0152-4

Beurlen, H., Rhede, D., Da Silva, M. R. R., Thomas, R., Guimarães, I. P. (2009). Petrography, Geochemistry and Chemical Electron Microprobe U-Pb-Th dating of Pegmatitic Granites in Borborema Province, Northeastern Brazil: A Possible Source of Rare Element Granitic Pegmatites. Terrae, 6(1), 59-71.

Bowles, J. F. W., Howie, R. A., Vaughan, D. J., Zussman, J. (2011). Non-Silicates: Oxides, Hydroxides and Sulphides. 2. ed. Londres: The Geological Society. v. 5.

Brito Neves, B. B., Santos, E. J., Van Schmus, W. R. (2000). Tectonic History of the Borborema Province. In: U. G. Cordani, E. J. Milani, A. Thomaz Filho, D. A. Campos (Eds.), Tectonic Evolution of South America. Rio de Janeiro: SBG, p. 151-182.

Brown, C. (1999). Mineralogy of NYF granitic pegmatites. In: The Eugene E. Foord Memorial Symposium on NYF-type Pegmatites (Denver). Canadian Mineralogist. 37, 848-849. Disponível em: <https://pdfs.semanticscholar.org/1da8/ ab3837cf31659a06c516ac77318d1ed54b47.pdf>. Acesso em: 10 ago 2020.

Černý, P. (2002). Mineralogy of beryllium in granitic pegmatites. Reviews in Mineralogy \& Geochemistry, 50(1), 405-444. https://doi.org/10.2138/rmg.2002.50.10

Černý, P., Ercit, T. S. (2005). The classification of granitic pegmatites revisited. Canadian Mineralogist, 43(6), 2005-2026. https://doi.org/10.2113/gscanmin.43.6.2005

Černý, P., Fryer, B. J., Chapman, R. (2001). Apatite from granitic pegmatite exocontacts in Moldanubian serpentinites. Journal of the Czech Geological Society, 46(1-2), 15-20.

Černý, P., Harris, D. C. (1978). The Tanco pegmatite at Bernic Lake, Manitoba. XI, Native elements, alloys, sulfides, and sulfosalts. Canadian Mineralogist, 16(4), 625-640. 
Da Silva, M. R. R., Höll, R., Beurlen, H. (1995). Borborema Pegmatitic Province: geological and geochemical characteristics. Journal of South America Earth Sciences, 8(34), 355-364. https://doi.org/10.1016/0895-9811(95)00019-C

Dantas, E. L. (1997). Geocronologia U-Pb e Sm-Nd de terrenos arqueanos e paleoproterozoicos do Maciço Caldas Brandão, NE do Brasil. Tese (Doutorado). Rio Claro: Instituto de Geociências e Ciências Exatas - UNESP.

Ferreira, J. A. M., Albuquerque, J. P. T. (1969). Sinopse da geologia da Folha Seridó. Recife: SUDENE, DRN/DG. Série Geológica - Boletim 18.

Ferreira, V. P., Sial, A. N., Jardim de Sá, E. F. (1998). Geochemical and isotopic signatures of Proterozoic granitoids in terrenes of the Borborema structural province, northeastern Brazil. Journal of South America Earth Sciences, 11(5), 439-455. https://doi.org/10.1016/S0895-9811(98)00027-3

Foord, E. E., Shawe, D. R. (1989). The $\mathrm{Pb}-\mathrm{Bi}-\mathrm{Ag}-\mathrm{Cu}-$ (Hg) chemistry of galena and some associated sulfosalts: a review and some new data from Colourado, California and Pennsylvania. Canadian Mineralogist, 27(3), 363-382.

Glass, J. J., Jahns, R. H., Stevens, R. E. (1944). Helvite and danalite from New Mexico and the helvite group. The American Mineralogist, 29(5-6), 163-191.

Guimarães, I. P., Brito, M. F. L., Lages, G. A., Silva Filho, A. F., Santos, L., Brasilino, R. G. (2016). Tonian granitic magmatism of the Borborema Province, NE Brazil: A review. Journal of South American Earth Science, 68, 97-112. https:// doi.org/10.1016/j.jsames.2015.10.009

Guimarães, I. P., Da Silva Filho, A. F. (1998). Nd- and Srisotopic and $\mathrm{U}-\mathrm{Pb}$ geochronologic constraints for the evolution of the shoshonitic Brasiliano Bom Jardim and Toritama complexes: evidence for a Transamazonian enriched mantle under Borborema tectonic province, Brazil. International Geology Review, 40(6), 500-527. https://doi.org/10.1080/00206819809465221

Hackspacher, P. C., Van Schums, W. R., Dantas, E. L. (1990). Um embasamento transamazônico na província Borborema. $X X X V I$ Congresso Brasileiro de Geologia. Natal: SBG-NE, p. 2683-2696.

Jardim de Sá, E. F. (1994). A Faixa Seridó (Província Borborema, NE do Brasil) e o seu significado geodinâmico na Cadeia Brasiliana/Pan-Africana. Tese (Doutorado). Brasília: Instituto de Geociências - UnB.

Landes, K. K. (1933). Origin and Classification of Pegmatites. American Mineralogist, 18(3), 95-103.
Lira Santos, G., Souza, I. M. B. A., Barreto, S. B., Araújo Neto, J. F., Müller, A. (2020). The Serra Branca Amazonite Pegmatite of the Vieirópolis pegmatite field, Paraíba, Brazil - a new and unusual megacrystic amazonite deposit. The Canadian Mineralogist, no prelo.

London, D. (2008). Pegmatites. Canada: The Canadian Mineralogist, Special Publication.

London, D. (2018). Ore-forming processes within granitic pegmatites. Ore Geology Reviews, 101, 349-383. https:// doi.org/10.1016/j.oregeorev.2018.04.020

Martin, G. R., De Vito, C., Pezzota, F. (2008). Why is amazonitic K-feldspar an earmark of NYF-type granitic pegmatites? Clues from hybrid pegmatites in Madagascar. American Mineralogist, 93(2-3), 263-269. https://doi.org/10.2138/am.2008.2595

Martin-Izard, A., Paniagua, A., Moreiras, D., Acevedo, R. D., Marcos-Pascual, C. (1995). Metasomatism at a granitic pegmatite - Dunite contact in Galicia: The Franqueira occurrence of chrysoberyl (alexandrite), emerald, and phenakite. The Canadian Mineralogist, 33(4), 775-792.

Medeiros, V. C. (Ed.). (2008). Geologia e Recursos Minerais da Folha Sousa SB.24-Z-A. Escala 1:250.000. Recife: CPRM.

Meunier, A. R. (1964). Succession stratigraphique et passages lateraux dus au metamorphisme dans la Série Ceará, Antecambrien du Nord-Est brésilien. Comptes Rendus Mathematique Academie des Sciences, 259, 3796-3799.

Mindat. Portal. Disponível em: <https://www.mindat.org/ min-3188.html>. Acesso em: 18 maio 2020.

Neves, S. P., Bruguier, O., Bosh, D., Silva, J. M. R., Mariano, G. (2008). U-Pb ages of plutonic and metaplutonic rocks in southern Borborema Province (NE Brazil): timing of Brasiliano deformation and magmatism. Journal of South American Earth Sciences, 25(3), 285-297. https://doi. org/10.1016/j.jsames.2007.06.003

Neves, S. P., Mariano, G. (1999). Assessing the tectonic significance of a large-scale transcurrent shear zone system: The Pernambuco lineament, northeastern Brazil. Journal of Structural Geology, 21(10), 1369-1383. https://doi. org/10.1016/S0191-8141(99)00097-8

Neves, S. P., Vauchez, A., Feraud, G. (2000). Tectonothermal evolution, magma emplacement, and shear zone development in the Caruaru area (Borborema Province, NE Brazil). Precambrian Research, 99(1-2), 1-32. https://doi. org/10.1016/S0301-9268(99)00026-1 
Ragu, A. (1994). Helvite from the French Pyrénées as evidence for granite-related hydrothermal activity. The Canadian Mineralogist, 32(1), 111-120.

Santos, E. J. (1995). O complexo granítico Lagoa das Pedras: acresção e colisão na região de Floresta (Pernambuco), Província Borborema. Tese (Doutorado). São Paulo: Instituto de GeociênciasUSP. https://doi.org/10.11606/T.44.1995.tde-28102015-094036

Santos, E. J., Souza Neto, J. A., Silva, M. R. R., Beurlen, H., Cavalcanti, J.A. D., Silva, M. G., Dias, V. M., Costa, A. F., Santos, L. C. M. L., Santos, R. B. (2014). Metalogênese das porções norte e central da Província Borborema. In: M. G. Silva, M. B. Rocha Neto, H. Jost, R. M. Kuyumijan(Eds.), Metalogênese das provincias tectônicas brasileiras, 343-388. Belo Horizonte: CPRM.

Seaman, D. M. (1974). Sulphides and Sulphosalts in Pegmatite. Rocks \& Minerals, 49(7-8), 435-438.

Silva, J. M. R., Mariano, G. (2000). Geometry and kinematics of the Afogados da Ingazeira shear zone, northeast Brazil. International Geology Review, 42(1), 86-95. https://doi. org/10.1080/00206810009465071

Silva Filho, A. F., Guimarães, I. P., Santos, L., Armstrong, R., Van Schmus, W. R. (2016). Geochemistry, U-Pb geochronology, Sm-Nd and $\mathrm{O}$ isotopes of ca. $50 \mathrm{Ma}$ long Ediacaran High-K Syn-Collisional Magmatism in the Pernambuco Alagoas Domain, Borborema Province, NE Brazil. Journal of South American Earth Sciences, 68, 134-154. https://doi.org/10.1016/j.jsames.2015.12.013

Soares, D. R., Beurlen, H., Silva, M. R. R., Gonzaga, F. A. S., Santos Filho, J. I., Oliveira, H. B. L. (2018). Variedades gemológicas de minerais da Província Pegmatítica da Borborema, NE do Brasil: Uma síntese. Estudos Geológicos, 28(1), 56-71. https://doi.org/10.18190/19808208/estudosgeologicos.v28n1p56-71

Souza, I. M. B. A., Guimarães, I. P., Barreto, S. B., Santos, G. L., Araújo Neto, J. F. (2020). Whole-rock and mineral chemistry characterization of contrasting granitoids, constraints on the source of the Vieirópolis NYF-type pegmatites, Northeastern Brazil. Brazilian Journal of Geology, 50(2), 1-23. https://doi.org/10.1590/2317-4889202020190083

Souza, J. V. (1985). Geologia dos pegmatitos de metais raros da região We NW de Solonópole - CE. Fortaleza. Tese (Concurso para Professor Titular). Ceará: Departamento de Geologia-UFC.

Speer, J. A. (1984). Micas in igneous rocks. In: S. W. Bailey (Ed.). Micas: Reviews in Mineralogy, 13, 299-356. Washington, D.C.: Mineralogical Society of America.
Van Schmus, W. R., Brito Neves, B. B., Hackspacher, P. C., Babinski, M. (1995). U/Pb and Sm/Nd geochronologic studies of the eastern Borborema Province, Northeast Brazil: initial conclusions. Journal of South American Earth Sciences, 8(3-4), 267-288. https://doi.org/10.1016/0895-9811(95)00013-6

Van Schmus, W. R., Kozuch, M., Brito Neves, B. B. (2011). Precambrian history of the Zona Transversal of the Borborema Province, NE Brazil: Insights from Sm-Nd and U-Pb geochronology. Journal of South American Earth Sciences, 31(2-3), 227-252. https://doi.org/10.1016/j.jsames.2011.02.010

Van Schmus, W. R., Oliveira, E. P., Silva Filho, A. F., Toteu, S. F., Penaye, J., Guimarães, I. P. (2008). Proterozoic links between the Borborema Province, NE Brasil and the Central African Fold Belt. Geological Society Special Publications, 294, 69-99. https://doi.org/10.1144/SP294.5

Vauchez, A., Egydio da Silva, M. (1992). Termination of a continentalscale strike-slip fault in partially melted crust: The West-Pemambuco shear zone, northeast Brazil. Geology, 20(11), 1007-1010. https://doi.org/10.1130/0091-7613(1992)020\%3C10 07:TOACSS\%3E2.3.CO;2

Vidal, F. W. H., Nogueira Neto, J. A. (2005). Minerais de Pegmatitos. In: F. W. H. Vidal, F. A. C. B. Sales, F. A. C. Roberto, J. F. Sousa, I. C. Mattos (Eds.). Rochas e Minerais Industriais do Estado do Ceará, p. 67-82. Fortaleza: CETEM/ UECE/DNPM/FUNCAP/SENAI.

Wise, M. A. (1999). Characterization and classification of NYFtype pegmatites. In: The Eugene E. Foord Memorial Symposium on NYF-type Pegmatites (Denver). Canadian Mineralogist, 37, 802-803. Disponível em: <https://pdfs.semanticscholar. org/1da8/ab3837cf31659a06c516ac77318d1ed54b47.pdf $>$. Acesso em: 10 ago. 2020.

Wise, M. A. (2013). The discrimination of LCT and NYF granitic pegmatites using mineral chemistry: a pilot study. $6^{\text {th }}$ International Symposium on Granitic Pegmatites. Maine, p. $156-157$.

Wise, M. A. (2017). Mineralogy and mineral chemistry of NYF-type granitic pegmatites. NGF Abstracts and Proceedings, 2, 177-180. Disponível em: < https://geologi.no/ konferanser/foredrag-abstracts/file/160-abstract-peg2017>. Acesso em: 10 ago. 2020.

Zito, G., Hanson, S. L. (2017). Genthelvite overgrowths on danalite cores from a pegmatite miarolitic cavity in Cheyenne Canyon, El Paso County, Colorado. The Canadian Mineralogist, 55(2), 195-206. https://doi.org/10.3749/ canmin. 1600066 